\title{
PENGARUH PROFESIONALISME GURU AGAMA TERHADAP PENDIDIKAN KARAKTER SISWA SEKOLAH DASAR ISLAM
}

\author{
DIKI KURNIAWAN \\ Universitas Cenderawasih \\ JI. Uncen, Kota Baru, Abepura, Kota Jayapura, Papua \\ dikikurniawan84@gmail.com
}

\begin{abstract}
:
This study aims to determine the influence of professionalism of religious teachers on the character education of students at SDIT Mitra Cendekia Indonesia Setu Tangerang Selatan, Banten. SDIT grade VI students totaling 30 people are the subject of research. This research uses two kinds of variables namely 1) free variable: professionalism of religious teachers, 2). Student character education. Data retrievel is obtained by using questionnaire with likers scale. The data analysis technique used is descriptive analysis to calculate the mean, median, standard deviation. As for hypothesis using simple linear regression analysis and coefficient of determination to know percentage of professionalism teachers adherent to the character education of students. The results of research indicate that there is a positive and sufficient influence between teachers professionalism to character aducation. I can be see from the $t$ count $>t$ table (2,948 > 2,04).
\end{abstract}

Keywords: teacher, character education, Islamic elementary school.

\section{PENDAHULUAN}

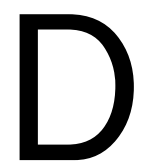
unia modern saat ini, termasuk Indonesia ditandai dengan perilaku yang benar-benar berada pada taraf yang mengkhawatirkan. Kejujuran, keadilan, kebenaran, tolong-menolong, dan kasih sayang sudah tertutup oleh penyelewengan, penipuan, penindasan, saling menjegal dan saling merugikan. Gejala kemerosotan perilaku tersebut dewasa ini bukan saja menimpa kalangan dewasa melainkan pula telah menimpa kalangan pelajar tunas-tunas muda.

Sebagian pelajar banyak yang berperilaku nakal, mabuk-mabukan, pesta obat-obatan terlarang, hamil diluar nikah. Menurut Lickona (terj, Juma, 2012:2028) ada sepuluh indikasi kemunduran kesadaran masyarakat yang perlu dibangkitkan agar perkembangan moral remaja menjadi lebih baik antara lain: kekerasan dan tindakan anarkis, pencurian, tindak curang, pengabaian terhadap aturan yang berlaku, tawuran antar siswa, ketidaktoleran, penggunaan bahasa yang tidak baik, kematangan seksual yang terlalu dini dan penyimpangannya serta sikap perusakan diri Hal ni tentu sangat bertolak belakang dengan fungsi pendidikan. Fungsi pendidikan sesuai dengan undang - undang Republik Indonesia nomor 20 tahun 2003 adalah mengembangkan kemampuan dan membentuk watak serta peradaban bangsa dalam rangka mencerdaskan kehidupan bangsa, bertujuan untuk berkembangnya potensi peserta didik agar menjadi manusia yang 
beriman dan bertakwa kepada Tuhan Yang Maha Esa, berakhlak mulia, sehat, berilmu, cakap, kreatif, mandiri dan menjadi warga negara yang demokratis serta bertanggung jawab.

Masalah-masalah yang terjadi erat kaitannya dengan pendidikan karakter. Karakter seseorang berbeda-beda karena dipengaruhi oleh factor keturunan dan factor lingkungan. Menurut Mukhlas samani (2012 :237) Karakter mengandung arti nilai dasar yang membangun pribadi seseorang, terbentuk baik karena pengaruh hereditas maupun pengaruh lingkungan, yang membedakannya dengan orang lain, serta diwujudkan dalam sikap dan perilakunya dalam kehidupan sehari - hari. Namun karakter dapat diubah jika lingkungan mendukung untuk mengubah karakter seseorang yang kurang baik menjadi lebih baik.

Pendidikan dapat berjalan dengan baik jika tripusat pendidikan dapat bersinergi dengan baik. Salah satu tripusat pendidikan adalah sekolah. Sekolah merupakan wahana untuk mentransfer pengetahuan dan mentransformasi afektif dan psikomotorik menjadi lebih baik. Untuk dapat mewujudkan tujuan pendidikan nasional berjalan dengan baik terutama mengenai membentuk karakter siswa yang baik maka peranan guru sangat dihandalkan karena salah satu tugas guru adalah mendidik, membina dan membimbing siswa.

Guru yang professional memahami karakteristik siswa yang dihadapinya. Oleh karena itu, ketika mengajar selalu memperhatikan siswanya. Mengetahui karakteristik siswa penting untuk menentukan bahan ajar yang akan diberikan. Seorang pendidik tidak boleh berhenti membentuk suasana pembelajaran kondusif bagi peserta didik supaya kualitas hasil belajarnya meningkat. Kompetensi yang harus dimiliki oleh seorang guru ada 4 yakni kompetensi kepribadian, kompetensi social, kompetensi paedagogie, dan kompetensi professional sesuai dengan undang - undang republik Indonesia nomor 14 tahun 2005.

Di sekolah dasar islam, guru diharapkan memberikan suri teladan kepada peserta didiknya. Biasanya peserta didik pada sekolah dasar melihat dan mencontoh tingkah laku gurunya. Guru yang berperan banyak dalam pendidikan karakter adalah guru pendidikan agama islam ( PAI ), Meskipun guru yang lainnya berperan. Hal ini disebabkan sumber materi pelajarannya dari al-quran dan hadist yang merupakan kitab suci umat islam dan rujukan cara bersikap, berbiccara dan bergaul seseorang yang beragama islam. Pendidikan agama islam jika dilihat dari bahan pelajarannya antara lain Alqur'an, aqidah, syariah, akhlak dan tarikh.

Sekolah dasar islam ( SDI ) merupakan sekolah yang bernuansa islami akan tetapi pelajarannya berbeda dengan madrasah ibtidaiyah ( $\mathrm{Ml}$ ), karena tidak semua pelajaran yang ada di madrasah ibtidaiyah di ajarkan, tergantung pada kebijakan dari sekolah dasar islam tersebut. Salah satu contoh sekolah dasar islam adallah SDI Mitra Cendekia Indonesia kurikulum khasnya antara lain habitual kurikulum, bahasa arab, tahfidz. Dan waktu pembelajaran adalah 7 jam sehari. Hal ini seharusnya memberikan keuntungan tersendiri bagi sekolah tersebut untuk 
memberikan pembinaan karakter yang lebih mendalam bagi peserta didiknya dengan di dukung oleh guru yang profesional dalam mendidik, mengajar dan melatih. Tujuan peneltian ini adalah 1 . Untuk mengetahui gambaran profesionalisme guru agama sekolah dasar islam, 2. Untuk mengetahui gambaran pendidikan karakter siswa sekolah dasar islam, 3. Untuk mengetahui pengaruh profesionalisme guru agama terhadap pendidikan karakter siswa sekolah dasar islam.

\section{METODOLOGI PENELITIAN}

Pendekatan yang digunakan dalam penelitian ini adalah pendekatan kuantitatif yakni suatu proses penelitian yang berhubungan dengan angka - angka atau data serta diolah berdasarkan rumus tertentu. Penelitian ini menggunakan instrument berupa angket yang diberikan kepada responden untuk menjawab penyataan angket.pengujian hipotesis menggunakan analisis regresi linier sederhana. Adapun kriteria penerimaan dan penolakan yakni $t$ hitung $>t$ tabel, maka hipotesa nol; ditolak sedangkan t hitung < t tabel maka hipotesa nol diterima . dan koefisiensi determinasi yang digunakan untuk mengetahui persentase derajat pengaruh variabel.

Penelitian dilakukan di Sekolah Dasar Islam Mitra Cendekia Indonesia Tangerang Selatan. Populasinya adalah kelas VI yang berjumlah 30 siswa. Data angket yang sudah diperoleh selanjutnya di analisis atau diolah dengan menggunakan bantuan software SPSS 16 untuk mengetahui pengaruh profesionalisme guru agama terhadap pendidikan karakter siswa sekolah dasar islam.

\section{HASIL PENELITIAN}

\section{Gambaran hasil penelitian}

1. Variabel profesiolisme guru agama

Berdasarkan perhitungan dengan bantuan komputer melalui program SPSS for windows maka diperoleh deskripsi/gambaran satatistik tentang variabel profesionalisme guru agama dapat disajikan sebagai berikut:

Tabel 6

\section{Gambaran Variabel Profesionalisme Guru}

\section{Statistics}

Profesionalisme

\begin{tabular}{|l|r|}
\hline Mean & 30.1667 \\
Std. Error of Mean & .40707 \\
Median & 30.0000 \\
Mode & 32.00
\end{tabular}




$\mid$\begin{tabular}{l|r} 
Std. Deviation & 2.22963 \\
Variance & 4.971 \\
Range & 9.00 \\
Minimum & 26.00 \\
Maximum & 35.00 \\
Sum & 905.00 \\
\hline
\end{tabular}

Histogram

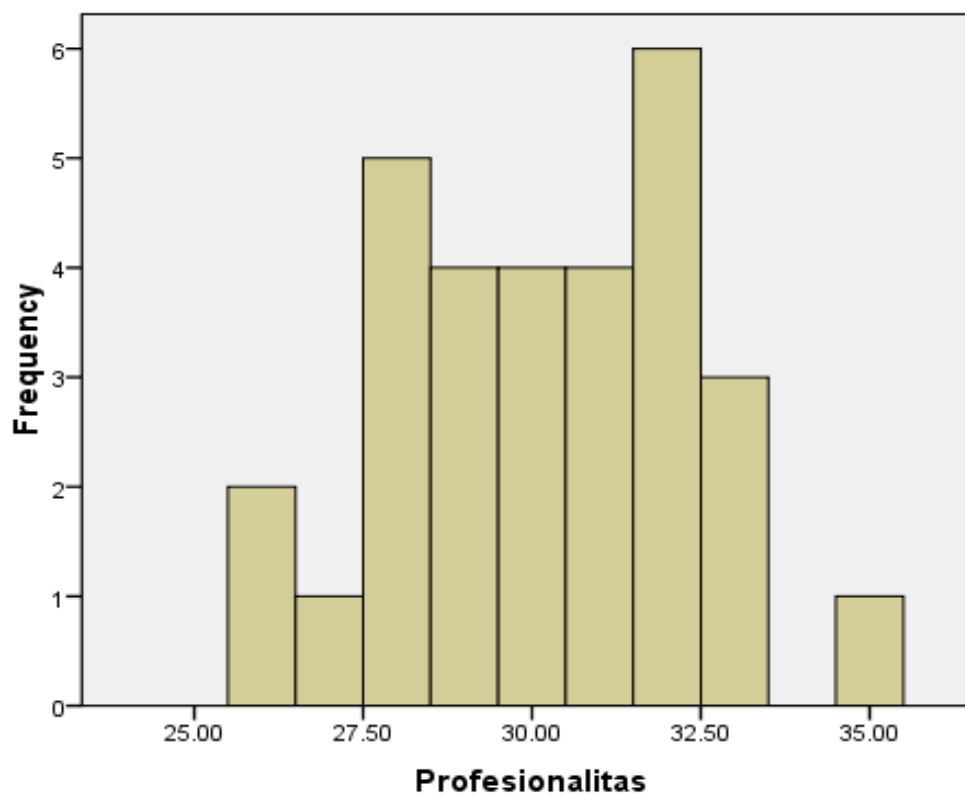

Mean $=30.17$

Std. $\underset{N=30}{\mathrm{~N}=2.23}$

Gambar 2

Histogram Variabel Profesionalisme

Penjabaran dari tabel dan histogram diatas antara lain

a. Perolehan skor antara 26 - 35 dengan jumlah responden 30 orang. nilai rata - ratanya ( mean ) adalah 30,16. Standar error 0,407, median ( nilai tengah ) 30,00, mode (nilai yang sering muncul) 32,00 standar deviasi ( akar dari varian) 2,29 , varian ( jumlah kuadrat semua deviasi nilai - nilai terhadap rata - rata ) 4,97 dan sum (jumlah isi data ) 905,0

b. Berdasarkan data diatas bahwa deskripsi statistik dari variabel profesionalitas guru dapat digolongkan dalam kategori yang cukup baik. Hal ini dilihat dari nilai rata - rata skor responden sebesar 30,16

2. Variabel Karakter Siswa

Berdasarkan perhitungan dengan bantua komputer melalui program SPSS for 
windows maka diperoleh deskripsi/gambaran statistik tentang variabel karakter siswa dapat disajikan sebagai berikut:

\section{Gambaran Variabel Karakter Siswa \\ Statistics}

karakter

\begin{tabular}{|l|r|}
\hline Mean & 32.6667 \\
Std. Error of Mean & .48974 \\
Median & 33.0000 \\
Mode & 33.00 \\
Std. Deviation & 2.68242 \\
Variance & 7.195 \\
Range & 9.00 \\
Minimum & 28.00 \\
Maximum & 37.00 \\
Sum & 980.00 \\
\hline
\end{tabular}

Histogram

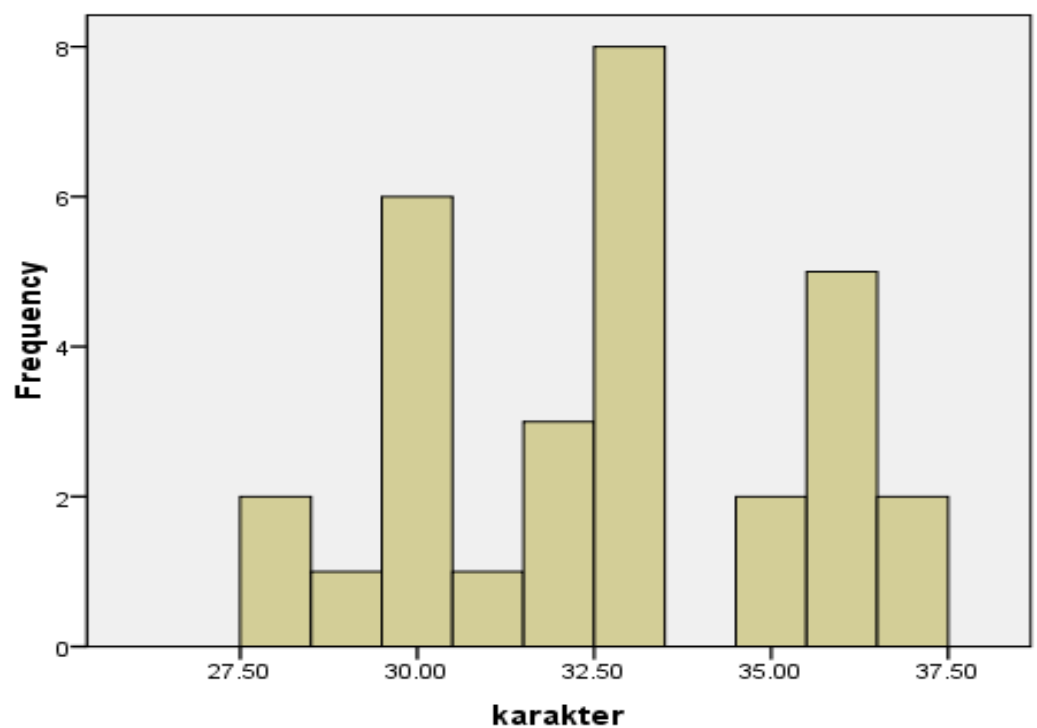
$\begin{aligned} \text { Mean } & =32.67 \\ \text { Std. Dev. } & =2.682\end{aligned}$ $\mathrm{N}=30$

Gambar 3

Histogram Variabel Karakter

Penjabaran dari tabel dan histogram diatas antara lain

a. Perolehan skor antara 28 - 37 dengan jumlah responden 30 orang. nilai 
rata - ratanya ( mean ) adalah 32,66. Standar error 0,489, median ( nilai tengah ) 33,00, mode (nilai yang sering muncul) 33,00 standar deviasi ( akar dari varian) 2,86 , varian ( jumlah kuadrat semua deviasi nilai - nilai terhadap rata - rata ) 7,19 dan sum (jumlah isi data ) 980,0

b. Berdasarkan data diatas bahwa deskripsi statistik dari variabel pendidikan karakter dapat digolongkan dalam kategori yang cukup baik. Hal ini dilihat dari nilai rata - rata skor responden sebesar 32,66

\section{PEMBAHASAN HASIL PENELITIAN}

Pengaruh Profesionalisme Guru Terhadap Pendidikan Karakter Siswa

a. Uji Signifikansi Koefisiensi Regresi ( t )

Berdasarkan pengelolaan data melalui perhitungan SPSS, didapat angka t hitung sebesar 2,948 pendidikan karakter ( contans) dan 2,203 profesionalisme guru, dengan signifikan ( sig) untuk kedua variabel, yaitu pendidikan karakter siswa 0,06 dan profesionalisme guru 0,036.

b. Koefisiensi Determinasi

Koefisien determinasi merupakan kuadrat dari nilai koefisien korelasi. Berdasarkan hasil perhitungan diperoleh nilai $\mathrm{R}$ square $=0,148$ atau sama dengan $14,8 \%$.

c. Persamaan Regresi

$Y=a+b X$

$Y=18,717+0,462 X_{1}$

Persamaan regresi tersebut dapat diartikan bahwa setiap kenaikan satu satuan variabel profesionalisme guru akan meningkatkan variabel pendidikan karakter siswa sebesar 0,462

d. Anova $\mathrm{F}$

Uji keberartian regresi menggunakan analisis variansi ( ANOVA) dengan bantuan aplikasi perhitungan SPSS untuk komputer, diperoleh $\mathrm{F}$ hitung $=$ 4,854 dan $F$ tabel $=3,354$ dengan taraf $(\alpha)$ 0,05. Dengan demikian $F$ hitung $>$ $F$ tabel . hal ini menunjukan Ho ditolak dan Ha di terima

Uji - t antara profesioanlisme guru agama terhadap pendidikan karakter yang memiliki t hitung 2,948 sedang t tabel sebesar 2,04, maka dapat disimpulkan bahwa t hitung $>\mathrm{t}$ tabel, sehingga kedua variabel antara pengaruh profesionalitas guru terhadap pendidikan karakter signifikan/berarti.

\section{PENUTUP}

\section{Kesimpulan}

1. Deskripsi statistik dari variabel profesionalitas guru dapat digolongkan dalam kategori yang cukup baik. Hal ini dilihat dari nilai rata - rata skor responden sebesar 30,16 
2. deskripsi statistik dari variabel pendidikan karakter dapat digolongkan dalam kategori yang cukup baik. Hal ini dilihat dari nilai rata - rata skor responden sebesar 32,66

3. Berdasarkan perhitungan dengan bantuan program SPSS 16 maka dapat diperoleh bahwa adanya pengaruh profesionalisme guru agama terhadap pendidikan karakter siswa . hal ini dibuktikan dengan t hitung > t tabel, ( 2,948 $>2,04$ ).

\section{Saran}

1 Guru PAl diharapkan dalam memberi materi tidak hanya satu metode tetapi dengan beberapa macam metode sehingga peserta didik dapat memahami materi dan tidak menimbulkan kebosanan bagi peserta didik.

2 Guru PAI di harapkan memberikan contoh kepada peserta didik karena peserta didik memerlukan aplikasi bukan materi saja.

3 Kepala sekolah dan guru PAI diharapkan memperdalam ilmu pendidikan sehingga akan menambah kualitas lulusan yang ada. Karena dengan adanya pengalaman atau pengetahuan yang bertambah maka kepala sekolah dan guru PAI dapat mencari solusi yang terbaik dalam pembinaan karakter siswa.

\section{DAFTAR PUSTAKA}

As, Asmaran, Pengantar Studi Akhlak , Jakarta : Rajawali Pers, 1992.

Dahlan, Sitti Salmiah, Manajemen Pendidikan Islam, Ciputat: Rabbani Press, 2011.

Fadli, Ahmad HS, Organisasi \& Administrasi , Jakarta : Manhalun Nasyi-In Press, 2011.

Kesuma, Dharma , dkk, Pendidikan Karakter kajian teori dan praktik di sekolah, Bandung: Remaja Rosdakarya, 2011.

Lickona ,Thomas, Education For Character Mendidik Untuk Membentuk Karakter Bagaimana Sekolah Dapat Memberikan Pendidikan Tentang Sikap Hormat dan Tanggung Jawab, jakarta : Bumi Aksara, 2012.

-----, Character Matters Persoalan Karakter Bagaimana Membantu Anak Mengembangkan penilaian yang baik, Integritas, dan Kebajikan Penting lainnya., Jakarta : Bumi Aksara, 2012.

Masruri, Negatif Learning, Solo: Era Adicitra Intermedia, 2011.

Moeliono , Anton , Kamus Besar Bahasa Indonesia, Jakarta : balai Pustaka, 1996

Mulyana, E, Manajemen Berbasis Sekolah Konsep, Strategi, dan Implementasi, Bandung : Remaja Rosda karya, 2011.

Muslich, Masnur, Pendidikan Karakter Menjawab Tantangan Krisis Multidimensional, Jakarta: Bumi Aksara, 2011. 
Nata, Abuddin, Akhlak Tasawuf, Jakarta : Raja Grafindo persada, 2012.

Ramayulis, Metodologi Pendidikan Agama Islam, Jakarta : Kalam Mulia, 2010.

Samani, Muchlas dan Hariyanto, Konsep dan Model Pendidikan Karakter, Bandung:

Remaja Rosdakarya, 2011.

Siregar, Syofian Statistik Parametik Untuk Penelitian Kuantitatif Dilengkapi Dengan Perhitungan Manual dan Aplikasi SPSS Versi 17, Jakarta : Bumi Aksara, 2013.

Sugiyono, Statistika Untuk Penelitian, Bandung : Alfabeta, 2012.

Sukmadinata , Nana Syaodih, Metode Penelitian Pendidikan, Bandung : Remaja Rosdakarya, 2010.

Undang - undang Republik Indonesia Nomor 14 tahun 2005 Tentang Guru dan Dosen , Bandung : Fermana, 2006.

Undang- undang Republik Indonesia nomor :20 tahun 2003 tentang SISDIKNAS, Bandung : Fermana, 2006.

Usman, Moh. Uzer Menjadi Guru Profesional, Bandung : Remaja Rosdakarya, 2011. Zainuddin, A. dan Muhammad Jamhari, Al - Islam 2 : Muamalah dan Akhlak, Bandung: Pustaka Setia, 1999. 